\title{
INDICE I.1.2.2
}

Prefazione $\quad$ V

$\begin{array}{ll}\text { Criteri editoriali } & \text { VI }\end{array}$

Curatori IX

Revisori dei papiri $\quad X$

Siglorum et compendiorum explicatio $\quad$ XI

Conspectus librorum XIII

ALEXIS 3

1 - P.Oxy. XV 1801, col. II 22-27. Voce di lessico (Hesione, fr. 90 K.-A.) 9

$\begin{array}{ll}\text { ANACREON } & 19\end{array}$

1 - P.Oxy. XXII 2321. Note marginali 27

2 - P.Oxy. LIII 3695. Note marginali 29

3 - P.Oxy. LIV 3722. Commentario 32

4 (?) - P.Oxy. LXV 4454. Commentario ad Anacreonte (?) 143

5 - P.Ryl. I 35. Nota su Anacreonte 152

Index papyrorum $\quad 155$

Index tabularum 156 
